\title{
Managing multiple forms of employment in the construction sector: implications for HRM
}

'This is the peer reviewed version of the following article: Raja, J.Z., Green, S.D. and Leiringer, R., Dainty, A. and Johnstone, S. (2012). Managing multiple forms of employment in the construction sector: implications for HRM. Human Resource Management Journal, 23(3), 313-328. Which has been published in final form at:

http://onlinelibrary.wiley.com.eproxy1.lib.hku.hk/doi/10.1111/j.1748-8583.2012.00202.x/full.

This article may be used for non-commercial purposes in accordance With Wiley Terms and Conditions for self-archiving'.

\begin{abstract}
The construction industry is one of the largest and most complex industrial sectors in the UK. The industry's failure to adopt progressive human resource (HR) practices is routinely blamed on the challenges of operating in a fragmented, project-based environment reliant on subcontracting. This research examines the extent to which existing HR theory accounts for the particular employment context of project-based organisations operating in volatile markets. Drawing upon case study research from two different divisions within a large contracting firm, this article explores the extent to which different contracting arrangements impinge on attempts to reposition human resource management (HRM) as a strategic function along the business partnering model. Elevating the role of the HR function is found to be difficult to reconcile with the concurrent demands of managing multiple forms of employment arrangements. The research reveals a need for HRM models that account for the specificities of complex, differentiated organisations that operate in multiple environments.
\end{abstract}

\section{INTRODUCTION}

Project-based organisations are becoming more common in a variety of sectors and are attracting increasing attention from researchers (e.g.Midler, 1995; Whittington et al., 1999; Davies and Hobday, 2005; Söderlund and Bredin, 2006). Despite interest in the challenges faced by project-based organisations, limited attention has been given to HRM in project-based environments, and the extent to which this challenges conventional thinking (cf. Söderlund and Bredin, 2006). The links between an organisation's project operations and HR practices are presently not well understood and do not figure highly on the current management agenda (Bredin and Söderlund, 2006). This article takes as its point of departure the contention that models derived from centralised homogeneous firms, working in relatively stable environments, are unsuitable for the complexity of project-based organising; and that there is a need for a shift in emphasis from viewing firms as 
homogeneous unitary entities and instead focus on the challenges of enacting HRM within dynamic environments (cf. Raja et al., 2010).

The construction sector is in many ways the epitome of a project-based industry, and project-based organisational forms have long been the norm. It is also one of the largest and most people-reliant sectors, and yet it is repeatedly argued that the industry lags behind other sectors when it comes to HR policies and practices (Druker and White, 1995; Dainty et al., 2007a). This is typically attributed to contextual factors that distinguish construction organisations from those operating within more stable environments. These include fluctuations in demand that encourage large construction firms to focus on numerical flexibility, and a short-term focus on price often at the expense of longer term employment considerations. The focus on numerical flexibility translates directly to an extensive reliance on subcontracting, often limiting the directly employed workforce to a small core of professional managers (Winch, 1998a). Other factors include the geographical and spatial distribution of organisational operations, and the disparate and transient nature of the workforce; these characteristics can in themselves be construed to be a product of the short-term project environment (Riley and Clare-Brown, 2001). Such arguments are widely recognised, but little to date has been made of the tendency for large construction firms to operate concurrently in multiple markets.

Notwithstanding established debates about the negative influence of short-term project environments, major clients in both the public and the private sectors have in recent years sought to establish longer term 'framework' agreements with selected contractors. Such frameworks arguably provide contractors with greater certainly of work, thereby potentially providing a more conducive context for construction firms to develop and invest in their HR functions along the "business partnering model' (Ulrich, 1997; Ulrich and Brockbank, 2005). In this article, we examine the extent to which the new operating context defined by long-term 'framework agreements' influences the modernisation of the HR function within construction firms. In doing so, we shed light on the challenges experienced by HR managers as they seek to configure their professional identity as 'business partners' (cf. Ulrich, 1997; Caldwell, 2003; Francis and Keegan, 2006; Wright, 2008; Keegan and Francis, 2010; Pritchard, 2010; McCracken and Heaton, 2012). The article also begins to address the lack of theorising in terms of the way HRM is shaped and patterned by the increasing prevalence of project-oriented organisations (see Bredin and Söderlund, 2006; Söderlund and Bredin, 2006; Huemann et al., 2007).

\section{CONSTRUCTION AS A CONTEXTUAL ARENA FOR STRATEGIC HR PRACTICE}

\section{The construction HR landscape}

The construction sector's regressive approach to HRM is widely documented. Studies have repeatedly contended that the dominant culture of the construction industry emphasises a model that treats people as a cost that is to be minimised (e.g. Druker and White, 1995; Druker et al., 1996; Green, 2002), with HRM as a low priority. The construction sector's supposed failure when it comes to 'people issues' has been a recurring theme of government reports on how to improve the performance of the industry since the Emmerson Report of 1962, which exhorted firms to adopt a longer term view to ensure increased stability of employment (Murray and Langford, 2003). In 1998, 
the government-sponsored task force led by Sir John Egan concluded that the UK construction industry is underachieving and that a 'commitment to people' is vital for its future (DETR, 1998: 4). Yet, the extent to which institutionally embedded practices may be reversed through such industrylevel 'attitudinal change' programme remains debatable (cf. Ness, 2010).

Rather than lay the blame for retrogressive HR on outmoded attitudes, an alternative perspective suggests that the sector's investment in HRM is hampered by a continued reliance on competitive tendering, which denies contractors certainty regarding continuity of work (Green and May, 2003) and the extensive utilisation of non-standard forms of employment (Forde and MacKenzie, 2007), which is arguably necessitated by extreme fluctuations in workloads that project-based working inevitably engenders. Both of these have acted to disincentivise investment in progressive HR practices with the sector. Indeed, it is clear that the quest for the so-called 'efficiency' gains from compulsory competitive tendering (CCT), which for so long was the backbone of public sector procurement policies, took priority over any agenda for a stable workforce. The implementation of CCT resulted in an increased use of temporary contracts for employees, reduction in union influence and worsening terms and conditions of employment (Colling, 1993; Sachdev, 2001). The end result is that construction firms tend to avoid taking responsibility for managing or 'carrying' a large workforce. Instead, firms have become exemplars of the hollowed-out 'flexible' firm, employing very few operatives directly (cf. Atkinson, 1984). Lockyer and Scholarios (2007) show how this causes power to be devolved away from centralised personnel departments to the project level, thereby increasing the informality of HR processes. Responsibility for skills development is similarly devolved and often rests on the shoulders of the individual worker (Dainty et al., 2007b). The corollary of these structural characteristics and institutionally embedded practices challenges elevating the role of HRM as a strategic driver. Indeed, the dominant perception of HR within the sector remains as an auxiliary activity that does not merit serious attention in the minds of other managers and professionals (cf. Legge, 1978).

\section{Framework agreements and the potential for more progressive approaches to HRM}

Despite deeply ingrained practices that shape the dominant HR orthodoxy within construction, changes in procurement strategies are clearly discernable among large construction clients. Much has been made of the advent of 'framework agreements', which could potentially provide a more stable platform for elevating the strategic importance of HRM within construction organisations. The pressure for change is in part attributable to public client organisations being increasingly asked to do 'more for less', i.e. to produce more public value with fewer resources (cf. Grimshaw et al., 2005; House of Commons Treasury Committee, 2007). While public sector clients have in the past been restricted in their ability to issue long-term contracts due to the centrally imposed need for frequent market testing, this is now gradually changing, and private organisations are increasingly being involved in the provision of public goods and services (cf. Grimshaw et al., 2002, 2005).

The progressive privatisation of highway maintenance capabilities has, for example, affected the way in which both the Highways Agency (HA) and the Local Authorities (LAs) procure construction work. The HA has introduced a succession of procurement initiatives, such as Managing Agent Contractor (MAC) and Extended MAC with associated framework agreements to facilitate a service-oriented engagement between public and private sectors (Highways Agency, 2005). 
Despite the increasing prevalence of 'framework agreements', there remains little consistency in the way they are implemented. According to the Office of Government Commerce (OGC, 2006), framework agreements (under Article 32) are defined as:

'an agreement with suppliers, the purpose of which is to establish the terms of governing contracts to be awarded during a period, in particular with regard to price and quantity.'

The defining characteristic of such agreements is that they transcend individual contracts and - in theory - provide contractors with a greater degree of certainty regarding future workload. Frameworks are considered to be one of the most significant tools that LAs are adopting in construction procurement (Communities and Local Government, 2008). It is argued that they offer numerous benefits in comparison with competitive tendering to deliver sustained ongoing improvements. From a transaction costs perspective, framework agreements purportedly lead to a significant reduction in tendering costs. Clients are no longer obliged to negotiate, monitor and enforce a series of disconnected one-off individual contracts (cf. Williamson, 1975). Framework agreements also supposedly allow for continuous improvement within the context of a mutually supportive longer term relationship and the possibility of winning subsequent framework contracts. The emergence of a more trust-based relationship is argued to offer a greater potential for efficiency gains from which both parties may benefit (MacKenzie, 2008).

It is also apparent that framework agreements potentially provides construction firms with an opportunity to implement more progressive approaches to HRM, as greater predictability enables firms to plan for the future. The OGC (2006) Directive on framework agreements refers to statutory obligations relating to Transfer of Undertakings (Protection of Employment) Regulations (TUPE). Many of the issues relating to TUPE are a legacy of privatisation through which public sector workforces have been inherited by construction firms that are engaged as framework contractors. This trend is especially observable within the context of highway maintenance where several contractors have acquired large directly employed workforces through TUPE transfers. Such cases stand in contrast to the default reliance on a lean organisational structure supplemented by subcontracting. Contractors involved in highway maintenance are therefore once again developing the capability to manage a large unionised workforce, including the appropriate HR functions.

Nevertheless, there is a risk to both clients and contractors becoming too dependent on a single exclusive relationship, and clients tend to negotiate several concurrent framework agreements with different contractors. Construction firms are careful to limit their exposure to single clients and often continue to bid competitively for one-off projects, mitigating notions of any all-embracing 'culture change'. Thus, the tendency is for contracting firms to compete in different market sectors at the same time (Leiringer and Schweber, 2010). For example, one operating division within a given company may be very dependent upon frameworks; others will continue to compete for work on the basis of one-off competitive tendering. However, the implications of this organisational ambidexterity for institutionalised HR practices remain under-researched but undoubtedly present challenges for organisations seeking to service different resourcing needs through consistent HRM practices. 


\section{Framework agreements and 'business partnering'}

Attempts to implement more enlightened approaches to HRM within the context of framework agreements in the construction sector cannot of course be separated from broader debates regarding the status of the HR function and its perpetual search for legitimacy (e.g. Legge, 1978, 2005; Farndale and Brewster, 2005). Of particular note is the way HR professionals have sought to construct their role along the 'business partnering' model proposed by Ulrich (1997) and Ulrich and Brockbank (2005). The Chartered Institute of Personnel Development (CIPD) has sought to promote the business partnering model to elevate the HR function as a key enabler of strategic intent rather than as a passive administrative function (cf. Brown et al., 2004; CIPD Report, 2007). The longer term nature of relational contracting arrangements such as framework agreements may be viewed as an opportunity for HR practitioners to gain enhanced legitimacy (cf. Suchman, 1995) and to play a more active and strategic role along the lines advocated by the business partnering model. The extant literature discusses some of the challenges and tensions HR practitioners encounter in their role as business partners (cf. Truss et al., 2002; Caldwell, 2003; Francis and Keegan, 2006; Keegan and Francis, 2010; Pritchard, 2010), but less attention has been paid to business partnering in complex project-based organisations operating across disparate market sectors.

While framework agreements potentially provide an ideal platform for HR professionals in construction to reconfigure their roles as strategic 'business partners', this has not yet been subject to empirical scrutiny. Accordingly, we present a case study that explores the enactment of such a strategy within different operating divisions of a contracting firm: one division benefiting from the stability of frameworks, while the other continues to compete for one-off projects on the basis of competitive tendering. The case study contributes to wider debates by considering how HR theory may be informed by the particular contextual experiences of a contracting firm that operate concurrently in different markets with contrasting institutional environments.

\section{RESEARCH METHODOLOGY}

A qualitative in-depth case study method (Eisenhardt, 1989; Flyvberg, 2007) was adopted within two operating divisions of a major construction company (hereafter referred to as ConCo). The research sought to access the empirical realities of the HR functions of the two divisions. One of these divisions was firmly rooted in an operational environment dominated by competitive tendering, while the other division predominantly worked within longer term framework agreements. This afforded an opportunity to juxtapose two very different operational approaches - one based on operating successfully in a project-based environment and the other inherently aiming to avoid such unstable environments while managing TUPE issues resulting from multiple employment arrangements. Both operating divisions presented interesting scenarios in that they have undertaken to develop their HR functions along the business partnering model proposed by Ulrich (1997).

The research approach can be described as 'abductive' (Järvensivu and Törnroos, 2010), comprising extensive interchange between empirical findings and theoretical insights gained during the research process (cf. Orton, 1997; Dubois and Gadde, 2002). Such an approach involves a constant movement back and forth between theory and empirical insights to occupy the middle ground between induction and deduction (Peirce, 1998 [1903]; Järvensivu and Törnroos, 2010). The research began with a thorough literature review and identified a suitable case study organisation. Discussions were 
then held with key gatekeepers of the chosen company, including senior managers in the two operating divisions. The next phase aimed to understand the business context of the two operating divisions. Eighteen interviews were conducted with senior and middle management, and the questions focused on the respondents' backgrounds, experiences of the operating context, contracting arrangements and implications of this for HR practice. The data were subsequently coded and analysed in terms of emergent themes. Additional information was gleaned from two formal feedback sessions that were held with the interviewees and additional senior managers. This enabled the validity of the interpretation of the emergent findings to be tested with the research participants. Informal discussions with senior managers over the duration of the research also played an important role in the verification process.

Ten interviews were then conducted with specialist HR personnel from the two divisions. The interviews were structured around open-ended questions examining the evolution, role and structure of the HR function, the strategic contribution of the function, and the challenges of delivering HR services in the current operating environment. Other data sources included archival analysis of relevant in-house documentation together with dozens of informal conversations with participants. Finally, three feedback sessions with five of the company's senior managers consolidated interpretations across the different phases of the study. In total, 28 semi-structured interviews were conducted across ConCo, lasting between 60 and 150 minutes, and were coded and transcribed verbatim. Further insights were gained from interviews with two procurement specialists from the HA and a large LA.

\section{Company overview}

The case study firm is one of the UK's largest construction companies, operating in over 20 countries and considered to be a market leader in civil engineering and road infrastructure services. In common with the majority of contracting firms, the company has traditionally operated on the basis of a devolved corporate structure characterised by decentralisation and localised autonomy, with operating divisions frequently possessing their own distinct cultures and modes of operation. The policy of decentralisation has been crucial to the company's success but has also created operational silos (cf. Winch, 1998b).

The findings are presented within the two separate operating divisions. This enables us to depict the different contexts within which the HR functions operate (see Table 1 for an overview of operating divisions), and allows for a rich understanding of how the HR functions have evolved and the challenges they confront in attempting to modernise. 


\begin{tabular}{|c|c|c|}
\hline $\begin{array}{l}\text { Business } \\
\text { description }\end{array}$ & $\begin{array}{l}\text { Complex, high-profile infrastructure projects, e.g. } \\
\text { roads, rail and tunnels }\end{array}$ & Asset management and maintaining road infrastructure \\
\hline $\begin{array}{l}\text { Typical } \\
\text { clients }\end{array}$ & Large public sector clients & Local authorities/Highways Agency \\
\hline $\begin{array}{l}\text { Typical } \\
\text { contracts }\end{array}$ & Design and build & Framework agreements \\
\hline $\begin{array}{l}\text { Espoused } \\
\text { strategic } \\
\text { imperatives }\end{array}$ & Agility, flexibility and delivery & Customer focus and service quality \\
\hline Employees & $\begin{array}{l}\text { Approx. } 500 \text { directly employed, mostly } \\
\text { professionals and managers, high reliance on } \\
\text { subcontracting }\end{array}$ & $\begin{array}{l}2300+\text {, emphasis on direct employment, many blue-collar ex- } \\
\text { local authority employees. } 2 / 3 \text { production staff }\end{array}$ \\
\hline $\begin{array}{l}\text { HR } \\
\text { function }\end{array}$ & $\begin{array}{l}\text { Nine people centralised at divisional head office: } \\
\text { including the director of HR, two regional HR } \\
\text { managers (business partners) and five HR } \\
\text { administrative staff }\end{array}$ & $\begin{array}{l}25 \text { people, centrally and across projects, including } \\
\text { recruitment, learning and development, client-facing HR } \\
\text { business partners, } 3 \text { HR managers, } 5 \text { HR advisers and HR } \\
\text { administration }\end{array}$ \\
\hline
\end{tabular}

Table 1. Overview of operating divisions in ConCo

\section{FINDINGS}

\section{Competitive tendering and project-based environments: the case of CivilEngCo}

\section{Operating context}

CivilEngCo is a traditional civil engineering company involved in a portfolio of large-scale, complex infrastructure projects such as highways, railways, hospitals, airports, power stations and transport interchanges. It has a notable track record in the successful delivery of high-profile technically complex projects. This is considered to be an important factor in attracting and retaining high-calibre staff, albeit that at times, this comes at the expense of the division being characterised as 'hardnosed' and 'aggressive' by other operating divisions within ConCo. The division places great emphasis on being strategically agile and quick to respond to changing circumstances and has grown through acquisitions. Structural flexibility is considered essential to respond to fluctuations in demand, epitomising the hollowed-out 'flexible' firm (cf. Atkinson, 1984), with CivilEngCo typically managing and co-ordinating the delivery of infrastructure projects through an extended network of subcontractors. This is clearly described by the managing director: 
“. . you may find it's actually better to go to a number of different suppliers to provide guys that can work under our supervision, and that way you can manage ... [and] bring people in for relatively short timescales and disperse them" (Managing Director, CivilEngCo).

According to the head of business development, the business context requires CivilEngCo to be 'continuously identifying opportunities' for work and 'at the right time to actually undertake' projects. CivilEngCo also needs to manage 'fluctuating workloads' and 'political interference with projects', as the following quote illustrates:

“... projects that we've won and thought that we were going to be constructing now were delayed by what the Government politely calls the New Comprehensive Spending Review, which tends to put gaps in the programme... . if you're not careful, suppliers can starve to death during the middle of a programme of work" (Head of Business Development, CivilEngCo).

It is therefore not surprising that the need for structural flexibility is emphasised given the volatile nature of the environment in which CivilEngCo operates. Accordingly, CivilEngCo employs very few construction operatives, and of the approximately 500 employees, relatively few are based on construction sites.

\section{Evolution and role of the HR function}

The HR function within CivilEngCo remains centralised within the organisational structure and located within the head office of the operating division. The function recently rebranded itself as the ' $\mathrm{HR}$ department' and was described as being in a state of transition as it attempted to move from an 'old-fashioned' administratively orientated function to a fully functional HR department for the '21st century'. To this end, a new head of HR had been recruited to restructure the department in line with perceived best practice. Senior management had also actively recruited HR practitioners from outside of the construction sector. Much was made of the need to recruit 'professionalised HR staff' in contrast to the 'old-fashioned' personnel managers who had progressed up through the ranks from clerical to administrative roles. The new head of HR commented on her first impressions of the function:

“... it's almost like it's been a little cocoon and the outside world doesn't sort of enter in here at all. I have to say when I came here I was quite shocked. I stupidly expected it to be like my other company" (Head of HR, CivilEngCo).

The extent to which personnel managers retained their traditional title or sought a difference in role and status with the rebranding of the HR function varied, but there was a clear divide between longer serving members of staff and HR practitioners who had recently arrived. The divide was further amplified through the remuneration packages offered to attract professionalised HR managers to the company. While senior management had actively instigated changes in restructuring the personnel function through recruiting new HR leadership in an attempt to modernise, those within the function itself were less enthusiastic towards change:

"... [we have] an Admin Manager who has been here for 20 years and I have repeated to my team they have to pick up the phone and call it Human Resources and she on 
purpose will not call it Human Resources [sic], she goes 'Personnel and Admin' which drives me absolutely bloody insane ..." (Head of HR, CivilEngCo).

In sharp contrast, the more recently recruited HR practitioners described themselves as working as 'business partners'. Moreover, they overtly acclaimed the need to 'add value' and be more 'strategic' in moving the business forward:

"...when I came in it was called Personnel which I was horrified about. Somebody said to me 'Well what's the difference?' I said 'That's the first essay you write on the CIPD:

what's the difference between Personnel and HR'. So I did a bit of explaining around and I believe that I have genuinely tried to work as a business partner, but there is still a significant amount of shift that needs to take place" (HR Manager, CivilEngCo).

There was a very clear divide between those that had been recruited recently and described themselves as HR professionals, and those who had been with the company for some time and still referred to the 'personnel department'. Tensions were clearly found to be running high between the two groups, with resultant feelings of insecurity and resistance. Longer serving members were proud of their expert knowledge of every policy detail, but the newly appointed HR managers sought engagement with the 'bigger picture' and wider business agenda. Longer serving members were clearly more focused on micro-level issues and concerned with there being no clearly defined structure within the function.

\section{Challenges}

It is clear that the divide within the HR function presented numerous challenges, especially in managing the expectations of the employees. Some interviewees clearly saw potential for the department to take a proactive strategic role for the benefit of the business, while others perceived no need to change. Senior management and operational staff also questioned the degree to which HR was able to support the new divisions and workforces adequately.

A further challenge was the perceived lack of broader commercial knowledge among HR specialists about the business, the nature of different projects and how they operate:

“. . . in terms of site labour, our HR function hasn't really grasped that area at all. So, we're left with almost individual projects deciding what's the right strategy for those projects" (Managing Director, CivilEngCo).

Many operational managers conceded that HR practitioners had a good knowledge of procedural issues relating to discipline, absenteeism and pay. However, their perceived lack of knowledge of the business undoubtedly damaged their credibility. This was particularly evident among middlemanagers, who showed a clear lack of buy-in to any suggestion that HR could play a more strategic role. Such suggestions were strongly refuted by the newly recruited HR staff, but at the same time, they readily conceded that any aspiration to play a more strategic role depended upon an understanding of the business. In this respect, they were actively visiting construction sites and attempting to work more closely with operational managers, but they suggested that ultimately, the most important requirement was understanding people rather than the industry per se. 
In essence, it was clearly discernible that a divide existed among operational managers and HR practitioners in terms of the latter's understanding of the industry. It was notable that many operational managers viewed HR practitioners' experience in other sectors to be of limited relevance. Little credibility was afforded to HR practitioners who claimed to be bringing in fresh ideas from elsewhere.

A particularly contentious issue centred on the calibre of HR staff. In particular, questions were raised around the lack of CIPD-qualified professionals within CivilEngCo and the possible impact this had on the function's capacity to add value to the business. The following example illustrates such concerns:

"They are acquiring more companies but the input and development isn't going to the HR team. So, we only have for instance two people qualified with a CIPD qualification out of a team of 8 or something like that.... That's almost unheard of in any other organisation that you go to" (HR Manager, CivilEngCo).

Many HR interviewees readily recognised the need to attain CIPD qualifications, although this alone would not necessarily improve their credibility in the eyes of the operational managers.

Paradoxically, junior HR staff argued that the company was reluctant to invest in their training and development to achieve CIPD accreditation, and felt undervalued and unsupported in their career development aspirations.

\section{Framework agreements and relatively stable environments: the case of}

\section{MaintenanceCo}

Operating context MaintenanceCo provides a range of asset management and maintenance services associated with highways, such as street lighting and traffic management. They have relatively few clients, with the majority of their work being done for the HA or LAs. In both cases, asset maintenance is routinely outsourced to contractors and frequently procured through framework agreements. MaintenanceCo clearly aims to align itself with clients' needs 'by delivering best value'. In this respect, the aspiration is to move from being a term maintenance contractor to an integrated service provider:

". . . the working relationship used to be one in which we had a contract with the client, the Highways Agency, and the Highways Agency had a contract with their agents, their managing agents, their consultants. And on a day-to-day basis, we reported directly to the client's agents. Now, we are the client's agents; we're part of the integrated team" (Managing Director, MaintenanceCo).

Employees in the division consider themselves as highly service-orientated and focused on the needs of the end customer. Particularly challenging is the need to work closely with joint venture partners and clients/consultants to deliver 'value-adding' outputs.

MaintenanceCo's overriding strategy was to move away from project-based environments toward longer term contracts. For example, the managing director commented that:

"It's not like project work, where a project lasts for two, three, four years. People move into the area, carry out the project, and then when the project ends, they disband.... Whereas in maintenance environment, it tends to be the same people that are there 
year in year out, and even when you win a new contract, you tend to take a large percentage of the incumbent staff, so there's continuity of people" (Managing Director, MaintenanceCo).

Thus, in contrast to the industry norm, MaintenanceCo has shifted to employing a large direct labour force of 2,300 operatives, many of whom are TUPE transfers from LAs. In addition, it had recently acquired a consultancy business and was developing a professional services capability to complement existing business streams.

\section{Evolution and role of the HR function}

MaintenanceCo's strategy was clearly successful in terms of achieving significant growth. Many of the contracts are on a 5-year term with options to extend. The need to respond to the challenges of the new business model was clearly acknowledged within HR, and it was accepted that significant changes in policies and procedures to support the organisation moving forward were necessary. Consequently, the HR function was being restructured along the shared service centre model with a range of automated processes and web-enabled applications. This work was led by an HR project manager who was responsible for overseeing the transformation of the function and for ultimately bringing MaintenanceCo in line with 'exemplar organisations' from other sectors. The intention was to centralise HR for easier co-ordination. In this respect, the HR team had recently restructured along the business partnering model to align with the needs of the business and be more proactive. For example, one HR business partner recollected:

"... one of the reasons why I was appointed, was that the HR department was at that time very reactive, not seen actively that much within the operating areas and the contracts and part of the reason I was brought in was to turn that around and become far more customer focused, business focused and to get the HR advisors working more as in a business partner model" (HR Business Partner 1, MaintenanceCo).

HR managers had thus begun to operate in their new role as business partners. A clear HR framework had already been established to support the business with issues such as training and development, succession planning, pay and reward, and equality and diversity. Two 'centres of excellence' in recruitment and learning and development had been established. Due to the growth of the business, the HR department needed continuously to recruit personnel with experience and relevant skill sets relating to the evolving demands of the business. Of particular note was the need to recruit professionals into client-facing roles.

In respect of giving voice to employee concerns, the HR team established a 'people forum', providing them with the opportunity to address issues with senior managers. Coverage included the planned $H R$ initiatives around equality and diversity and e-learning. While the HR function was indeed becoming much more involved in strategic matters, the day-to-day pressures of dealing with operational issues still accounted for a significant amount of HR managers' time, reflecting a degree of tension between strategic intent and operational reality.

\section{Challenges}

MaintenanceCo's strategy of avoiding exposure to unstable project-based environments means that they have become more sensitive to shifting procurement policies within LAs and the HA. The most 
notable challenge facing the division lies in managing its rapid expansion and subsequent growth in the directly employed diverse workforce. As already noted, many of the operatives were TUPE transfers from LAs necessitating significant effort in managing the associated 'cultural transition'.

Additional issues related to the integration of the various workforces that had been acquired through acquisitions, including having over 30 different terms and conditions of employment within MaintenanceCo. The HR director commented that it was:

"... virtually impossible to try and standardise all of those different Terms and Conditions, because the variability is so high ... the only way you are going to level them, is to level everybody up to the highest level. ... so we have to live with the ambiguity ..." (HR Director, MaintenanceCo).

Inevitably, having so many terms and conditions of employment raises numerous issues and complexities in terms of managing the workforce. Additional difficulties are created by the local authority contract cycle. Even with framework agreements, there is uncertainty regarding contract renewal. The potential for subsequent transfer of the workforce back to the public sector thereby constrains harmonisation of the terms and conditions of TUPE transfers. Somewhat paradoxically, it was also felt that the 5 -year contract cycle led to considerable insecurity and trepidation among the workforce nearing the end of a term. Thus, while much was made of the increased certainty of working in the context of a framework agreement, it was still considered difficult to foster cultural change and loyalty from the workforce. Although HR practitioners clearly articulated the desire to support the business by becoming a business partner, the reality was that considerable effort and time are consumed in dealing with the routine, operational work - especially relating to managing differing terms and conditions of employment.

\section{DISCUSSION: MANAGING IN DIFFERENT COMPLEX CONTEXTS}

The case study illustrates how the two divisions are attempting to modernise the HR function within different contracting environments. Arguably, the inherent uncertainties and complexities of the construction sector inevitably compromise any attempt to elevate the HR function. Nevertheless, there is evidence to suggest that contracting arrangements do to some extent influence the ways in which the HR function is embedded into the business. The HR model identified in CivilEngCo resembled an administrative function that provided clerical support to line managers. As Monks (1993) makes clear, this is not to argue that other roles and categories proposed were not relevant but that there was little evidence of them being undertaken. Employees within the HR department in CivilEngCo described themselves as perennially 'fighting fires' rather than being proactively involved in the business. Much of this was attributed to the cyclical nature of the business environment and to the consequent lack of certainty regard work flow. In contrast, MaintenanceCo operated in a different business environment and encountered different HR challenges. Whereas in CivilEngCo, the lack of credibility of the HR function was an issue, and this was not found to figure as prominently in MaintenanceCo. Within the latter division, dealing with day-to-day operational matters while at the same time attempting to be more strategic in orientation was found to be of greater concern. 
The desire for more strategic involvement was also expressed by senior HR respondents in CivilEngCo, but there was little evidence of any substantive shift having taken place in practice. Rather, the HR function lacked the legitimacy to promote meaningful strategic action. Of particular note is the way the HR function was based in the headquarters and largely divorced from the day-today realities of the project-based business. However, in MaintenanceCo, the adoption of a more strategic approach and contribution to business strategy was clearly discernible. MaintenanceCo had clearly made progress by developing the business partner approach and by making HR managers mobile between the different operational sites rather than being based centrally. It would seem that framework agreements may offer greater stability for restructuring the HR function along the lines of business partnering, although it would be naïve to suggest any sort of simplistic instrumental link.

Notwithstanding the shift to business partnering, MaintenanceCo has also been more successful in restructuring the HR function so that the shared services centre manages routine administrative work. In contrast, the restructuring process within CivilEngCo has encountered resistance from longer serving personnel and administrative managers, and lacked any overarching strategic framework within which HR should operate. The subjugated role of the HR function, where it is relegated to responding to resource requirements, reflects the wider construction industry tendency to rely on contingent labour at a project level (cf. Forde and MacKenzie, 2004). With the HR function remaining rooted within a reactive and largely operational paradigm, there is little scope for enacting the central tenets of business partnering as depicted in Ulrich's (1997) model. It also raises further questions around the concurrent enactment of very different HR strategies and the effects that this has across the business. It would seem, therefore, that current HRM theory fails to account for the needs of project-based organisations that emphasise fluidity and flexibility in the face of fluctuating demand cycles.

\section{Reconciling terms and conditions of employment}

The case study further highlights the significant challenges confronting the HR function in supporting operating divisions that operate in very different environments. While CivilEngCo avoided the inherent challenges of managing different terms and conditions of employment through subcontracting, MaintenanceCo has to contend with numerous terms and conditions of employment, many of which had been inherited under TUPE regulations. Both cases present significant challenges in the management of the employment relationship. Many other private sector firms also struggle with the relevant HR expertise 'for sustaining co-operative employment relations and thus delivering high standard services' (Grimshaw et al., 2002: 493). It would therefore be a mistake to overemphasise the extent to which these difficulties are unique to the construction sector. Nevertheless, in construction, the duration of contracts, the working in joint ventures and the inherent uncertainty surrounding future work all contribute to the difficulties in planning for the longer term.

Of particular note within MaintenanceCo was the admission by the HR director that it was unfeasible to manage over 30 different types of terms and conditions. Hence, it would seem that the TUPE protection offered to those transferring to MaintenanceCo was not considered sustainable in the longer term. The negotiated framework agreements were important in that they provide the context within which such TUPE transfers take place. Such agreements typically span 5 years, thereby providing a longer planning period than prevails within CivilEngCo. Nevertheless, uncertainty tended to increase toward the end of each framework agreement, and it was the existence of different 
directly employed workforces on different terms and conditions that was of more central importance in raising the status of the HR function.

It is therefore questionable whether framework agreements in themselves offer the means for greater investment in HR, especially when the need to reconcile terms and conditions is likely to be to the detriment of the majority of the workforce (cf. Cooke et al., 2004).

\section{Legitimising the role of 'business partnering'}

The wider literature is indicative of the enthusiasm with which HR practitioners have been adopting the 'business partnering' role in numerous sectors (cf. Caldwell, 2003; Wright, 2008; McCracken and Heaton, 2012). Yet, within ConCo, the legitimacy afforded toward the implementation of business partnering would seem to be dependent upon the existence of a large directly employed workforce. There is also evidence to support the contention that the business partner role undermines the possibility of a cohesive HR function (cf. Wright, 2008). The desire of HR practitioners to frame their role as 'business partners' was clearly evident in responses, although such arguments seemingly had little traction within CivilEngCo. While the shift to business partnering can be viewed as a means of enhancing the status and legitimacy of HR professionals, the role is found to be dependent upon acceptance by operational managers (Wright, 2008).

Operational managers in both divisions felt that HR professionals lacked understanding of the 'business', viewing their role as limited to checking details and to recording information on recruitment (Bresnen et al., 1985). While fresh HR insights and ideas were brought into the organisation by recruiting HR managers from other sectors, the lack of industry-specific knowledge worked against HR professionals being taken seriously. It is important to recognise that the criticism was by no means unidirectional; several respondents within HR questioned the ability of the operational managers to interview and recruit personnel into the business in accordance with the basic principles of employment law. This was of course much less of an issue within CivilEngCo due to the widespread reliance on subcontracting. Within this context, operational managers and HR professionals were working in isolation of one another, with no clear expectation of how a better working arrangement might be achieved. Once again, the fluidity of the construction business seems to challenge the applicability of mainstream theory to account for the varying operational needs and realities of such organisations.

\section{CONCLUSIONS}

The aim of this article was to provide critical insights into how different contracting arrangements influence the HR function. In doing so, we have revealed the limited strategic influence of the HR function within a leading player in the construction industry, but also how the operating context of the construction sector challenges the ability of mainstream HR theory to account for either the multiple uncertainties that confront such organisations or the multiple concurrent business models that they enact to cope with them. A major contributory factor in this regard has been the concurrent reliance on subcontracting within traditional contracting, coupled with moves toward longer term frameworks within other sectors. Clearly, contracting on such basis is unlikely to disappear, but as this article has revealed, such arrangements are now paralleled by new HR challenges that surround the delivery of longer term framework agreements. Thus, the reality for 
many construction companies is that they operate across multiple arenas; while parts of the business operate in project-based environments, others are striving to move away from them.

The ills of HRM in construction to date have been laid at the door of project-based environments and competitive tendering. Project-based organising and contracting on a project basis is increasingly common, and therefore there is a clear need for 'more sophisticated and fine-grained HR practices' within project-based organisations (cf. Söderlund and Bredin, 2006: 262), although there is little certainty about what such practices might look like in practice. There is then a clear need to further our understanding of how HRM is shaped and patterned in project-based organisations. Perhaps the core challenge to existing theory relates to the paradoxical situation faced by HR practitioners who are expected to cope with short-term exigencies on the one hand, and strategic support for longterm priorities, on the other hand. HR practitioners then find themselves so embroiled with administrative issues relating to terms of employment that little time remains for meaningful strategic input. Thus, there is no guarantee that frameworks will improve HR practice and, more specifically, the terms and conditions of construction operatives. Thus, it would seem that the construction sector still has some way to travel in terms of defining a more strategic role for HRM, and that HR theory has some way to go to account for the specificities of complex, differentiated project-based organisations that operate in multiple environments.

\section{Acknowledgements}

The work presented was funded primarily by the Engineering and Physical Sciences Research Council and the Economic and Social Research Council under Grant Numbers EP/C534220/1 and RES-331-270006. We would also like to thank the editor and two anonymous referees for their insightful comments.

\section{REFERENCES}

Atkinson, J. (1984). Emerging UK Work Patterns in Flexible Manning - The Way Ahead, IMS Report, No. 88, Brighton: Institute of Manpower Studies.

Bredin, K. and Söderlund, J. (2006). 'Perspectives on human resource management: an explorative study of the consequences of projectification in four firms'. International Journal of Human Resources Development and Management, 6: 1, 92-113.

Bresnen, M., Wray, K., Bryman, A., Beardsworth, A., Ford, J. and Keil, E. (1985). 'The flexibility of recruitment in the construction industry: formalization or recasualization?' Sociology, 19: 1, 108-124.

Brown, D., Caldwell, R., White, K., Atkinson, H., Tansley, T., Goodge, P. and Emmott, M. (2004). Business Partnering, A New Direction for HR, London: CIPD.

Caldwell, R. (2003). 'The changing roles of personnel managers: old ambiguities and new uncertainties'. Journal of Management Studies, 40: 4, 983-1004. 
CIPD Report (2007). The Changing HR Function: Transforming HR, London: CIPD.

Colling, T. (1993). 'Contracting public services: the management of compulsory competitive tendering in two county councils'. Human Resource Management Journal, 3: 4, 1-15.

Communities and Local Government (2008). The National Procurement Strategy for Local

Government - Final Report: Towards Public Service Transformation, London: Communities and Local Government.

Cooke, F.L., Earnshaw, J., Marchington, M. and Rubery, J. (2004). 'For better and for worse: transfer of undertakings and the reshaping of employment relations'. International Journal of Human Resource Management, 15: 2, 276-294.

Dainty, A., Green, S.D. and Bagilhole, B. (eds) (2007a). People and Culture in Construction: A Reader, Abingdon, Oxon: Taylor \& Francis.

Dainty, A.R.J., Grugulis, I. and Langford, D. (2007b). 'Understanding construction employment: the need for a fresh research agenda'. Personnel Review, 27: 3, 501-508.

Davies, A. and Hobday, M. (2005). The Business of Projects: Managing Innovation in Complex Products and Systems, Cambridge: Cambridge University Press.

DETR (1998). Rethinking Construction, [The Egan Report], Report of the Construction Task Force, London: Department of Environment, Transport and the Regions.

Druker, J. and White, G. (1995). 'Misunderstood and undervalued? Personnel management in construction'. Human Resource Management Journal, 5: 3, 77-91.

Druker, J., White, G., Hegewisch, A. and Mayne, L. (1996). 'Between hard and soft HRM: human resource management in the construction industry'. Construction Management and Economics, 14: 5, 405-416.

Dubois, A. and Gadde, L.-E. (2002). 'Systematic combining: an abductive approach to case research'. Journal of Business Research, 55: 7, 553-560.

Eisenhardt, K.M. (1989). 'Building theories from case study research'. Academy of Management Review, 14: 4, 532-550.

Farndale, E. and Brewster, C. (2005). 'In search of legitimacy: personnel management associations worldwide'. Human Resource Management Journal, 15: 3, 33-48.

Flyvberg, B. (2007). Five Misunderstandings about Case Study Research, London: Sage.

Forde, C. and Mackenzie, R. (2004). 'Cementing skills: training and labour use in UK construction'. Human Resource Management Journal, 14: 3, 74-88.

Forde, C. and Mackenzie, R. (2007). 'Getting the mix right? The use of labour contract alternatives in UK construction'. Personnel Review, 36: 4, 549-563.

Francis, H. and Keegan, A. (2006). 'The changing face of HRM: in search of balance'. Human Resource Management Journal, 16: 3, 231-249. 
Green, S.D. (2002). 'The human resource management implications of lean construction: critical perspectives and conceptual chasms'. Journal of Construction Research, 3: 1, 147-165.

Green, S.D. and May, S. (2003). 'Re-engineering construction: going against the grain'. Building Research and Information, 31: 2, 97-106.

Grimshaw, D., Vincent, S. and Willmott, H. (2002). 'Going privately: partnership and outsourcing in UK public services'. Public Administration, 80: 3, 475-502.

Grimshaw, D., Marchington, M., Rubery, J. and Willmott, H. (2005). 'Introduction: fragmenting work across organizational boundaries', in M. Marchington, D. Grimshaw, J. Rubery and H. Willmott (eds), Fragmenting Work: Blurring Organizational Boundaries and Disordering Hierarchies, Oxford: Oxford University Press.

Highways Agency (2005). Delivering Best Value Solutions and Services to Customers - HA Procurement Strategy Review 2005, Wetherby, UK: Highways Agency.

House of Commons Treasury Committee (2007). The 2007 Comprehensive Spending Review: Prospects and Processes, London: Stationery Office.

Huemann, M., Keegan, A.E. and Turner, J.R. (2007). 'Human resource management in the project oriented company: a critical review'. International Journal of Project Management, 25: 3, 312-320.

Järvensivu, T. and Törnroos, J.-A. (2010). 'Case study research with moderate constructionism: conceptualization and practical illustration'. Industrial Marketing Management, 39: 1, 100-108.

Keegan, A. and Francis, H. (2010). 'Practitioner talk: the changing textscape of HRM and emergence of HR business partnership'. International Journal of Human Resource Management, 21: 6, 873-898.

Legge, K. (1978). Power, Innovation, and Problem-Solving in Personnel Management, London: McGraw-Hill.

Legge, K. (2005). Human Resource Management: Rhetoric and Realities, Anniversary Edition, Basingstoke: Palgrave.

Leiringer, R. and Schweber, L. (2010). 'Managing multiple markets: big firms and PFI'. Building Research and Information, 38: 2, 131-143.

Lockyer, C. and Scholarios, D. (2007). 'The "rain dance" of selection in construction: rationality as ritual and the logic of informality'. Personnel Review, 27: 3, 528-548.

Mackenzie, R. (2008). 'From networks to hierarchies: the construction of a subcontracting regime in the Irish telecommunications industry'. Organization Studies, 29: 6, 867-886.

McCracken, M. and Heaton, N. (2012). 'From tucked away to joined at the hip: understanding evolving relationships within the HRBP model in a regional energy company'. Human Resource Management Journal, 22: 2, 182-198.

Midler, C. (1995). "'Projectification" of the firm: the Renault case'. Scandinavian Journal of Management, 11: 4, 363-375. 
Monks, K. (1993). 'Models of personnel management: a means of understanding the diversity of personnel practices'. Human Resource Management Journal, 3: 2, 29-41.

Murray, M. and Langford, D. (eds) (2003). Construction Reports 1944-98, Oxford: Blackwell.

Ness, K. (2010). 'The discourse of "respect for people" in UK construction'. Construction

Management and Economics, 28: 5, 481-493.

Office of Government Commerce (2006). 'Framework Agreements: OGC Guidance on Framework Agreements in the new procurement regulations'. January 2006. [Available at:

http://webarchive.nationalarchives.gov.uk/20100503135839/http://ogc.gov.uk/documents/guide_c ompetitive_dialogue.pdf] (accessed 6 June 2012).

Orton, J.D. (1997). 'From inductive to iterative grounded theory: zipping the gap between process theory and process data'. Scandinavian Journal of Management, 13: 4, 419-439.

Peirce, C.S. (1998 1903). 'Pragmatism as the logic of abduction', in Peirce Edition Project (ed.), The Essential Peirce: Selected Philosophical Writings, Vol. 2, Bloomington, IN: Indiana University Press, pp. 226-242.

Pritchard, K. (2010). 'Becoming a HR strategic partner: tales of transition'. Human Resource Management Journal, 20: 2, 175-188.

Raja, J.Z., Green, S.D. and Leiringer, R. (2010). 'Concurrent and disconnected change programmes: strategies in support of servitization and the implementation of business partnering'. Human Resource Management Journal, 20: 3, 258-276.

Riley, M.J. and Clare-Brown, D. (2001). 'Comparison of cultures in construction and manufacturing industries'. Journal of Management in Engineering, 17: 3, 149-158.

Sachdev, S. (2001). Contracting Culture: From CCT to PPPs: The Private Provision of Public Services and Its Impact on Employment Relations, London: Unison.

Söderlund, J. and Bredin, K. (2006). 'HRM in project-intensive firms: changes and challenges'. Human Resource Management, 45: 2, 249-265.

Suchman, M. (1995). 'Managing legitimacy: strategic and institutional approaches'. Academy of Management Review, 20: 3, 571-610.

Truss, C., Gratton, L., Hope-Hailey, V., Stiles, P. and Zaleska, J. (2002). 'Paying the piper: choice and constraint in changing HR functional roles'. Human Resource Management Journal, 12: 2, 39-63.

Ulrich, D. (1997). Human Resource Champions, Boston, MA: Harvard University Press.

Ulrich, D. and Brockbank, W. (2005). The HR Value Proposition, Boston, MA: Harvard University Press.

Whittington, R., Pettigrew, A., Peck, S., Fenton, E. and Conyon, M. (1999). 'Change and complementarities in the new competitive landscape: a European panel study, 1992-1996'.

Organizational Science, 10: 5, 583-600. 
Williamson, O.E. (1975). Markets and Hierarchies: Analysis and Anti-Trust Implications, New York: Free Press.

Winch, G.M. (1998a). 'The growth of self-employment in British construction'. Construction Management and Economics, 16: 5, 531-542.

Winch, G.M. (1998b). 'Zephyrs of creative destruction: understanding the management of innovation in construction'. Building Research and Information, 26: 4, 268-279.

Wright, C. (2008). 'Reinventing human resource management: business partners, internal consultants and the limits of professionalization'. Human Relations, 61: 8, 1063-1086. 